\title{
Relapse of Multiple Myeloma Presenting as Lower Lip Numbness
}

\section{اكتشاف انتكاسة ورم نقوي متعدد من خلال ظهور اخدرار للشفة السفلية}

يسرى الريامية، عبدالعزيز باكثير، خليل الفارسي، فيصل العزري

ABSTRACT: Multiple myeloma (MM) is an uncommon malignancy characterised by the proliferation of clonal plasma cells. There are few published reports describing the extramedullary presentation of MM manifesting primarily in the head and neck region. In addition, the occurrence of an isolated relapse of MM in these sites is exceedingly rare. We report a 56-year-old female who presented to the Sultan Qaboos University Hospital, Muscat, Oman, in 2010 with sudden-onset numbness of the lower lip. She had a history of MM in remission following chemotherapy and a bone marrow transplant. Clinical and radiographic examinations were indicative of a possible relapse of MM, which was subsequently confirmed by bone marrow aspiration and histopathological evaluation. This unique case highlights the unusual site of relapse of a haematolymphoid malignancy.

Keywords: Multiple Myeloma; Relapse; Head and Neck Neoplasms; Plasmacytoma; Case Report; Oman.

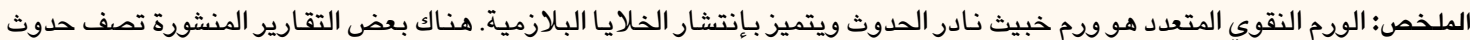

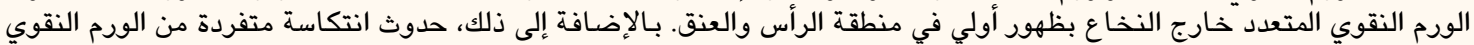

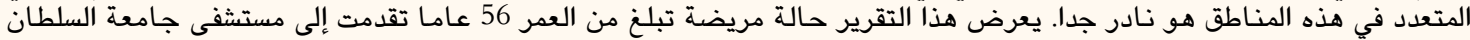

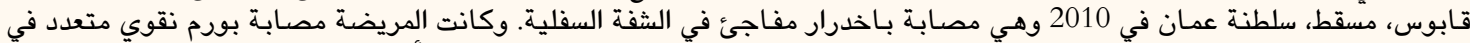

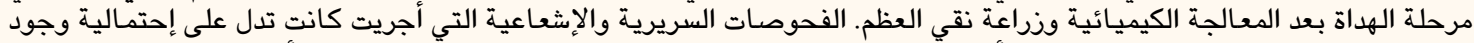

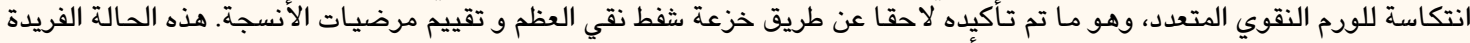

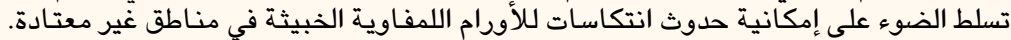
الكلمات المفتاحية: الورم النقوي المتعدد؛ انتكاسة؛ أورام الرأس والعنق؛ ورم البلازماويات؛ تقرير حالة؛ عمان.

$\mathrm{M}$ Ultiple MYelOMA (MM) IS AN AGGRESSive haematological malignancy arising from the monoclonal expansion of neoplastic plasma cells in the bone marrow. ${ }^{1-3}$ It tends to occur mostly in older patients, with men being twice as likely to be affected., ${ }^{2,3}$ MM usually occurs as a result of the progression from earlier conditions known as monoclonal gammopathy of undetermined significance (MGUS) and smouldering myeloma. ${ }^{2}$ It can also evolve from a more localised form of the disease, referred to as solitary plasmacytoma (either bony or soft tissue); tissue samples from both localised plasmacytomas and MMs provide identical histopathological pictures. ${ }^{2-4}$

MM is usually restricted to the bone marrow and may present clinically with a range of complex manifestations, including anaemia, bone pain due to generalised osteoporosis or focal lytic lesions secondary to osteolytic bone destructions, hypercalcaemia, renal dysfunction and a compromised immune system. ${ }^{5,6}$ Malignant plasma cells can escape the bone marrow microenvironment and proliferate at extramedullary sites; various sites such as the eyes, respiratory tract, testes, adrenal and thyroid glands, lymph nodes, skin and subcutaneous tissues, central nervous system and other organs have been reported in the literature. ${ }^{5-7}$ Extramedullary MM (EMM) can occur as a primary presentation or, more commonly, in a secondary form during progression or relapse of MM. ${ }^{6}$ The incidence of EMM ranges between $2-20 \% .{ }^{6,7}$ However, the occurrence of EMM in the oral and maxillofacial region is rare and infrequently reported, with varying degrees of symptoms including pain, swelling, bleeding, mobility of the teeth and nerve neuropathies. ${ }^{1,3,4}$

\section{Case Report}

A 56-year-old female patient was referred from the Haematology Department to the Oral \& Maxillofacial Surgery Unit of Sultan Qaboos University Hospital, Muscat, Oman, in 2010 due to sudden-onset numbness of the lower lip. The patient had first noticed the numbness 10 days previously. In 2008, the patient had 


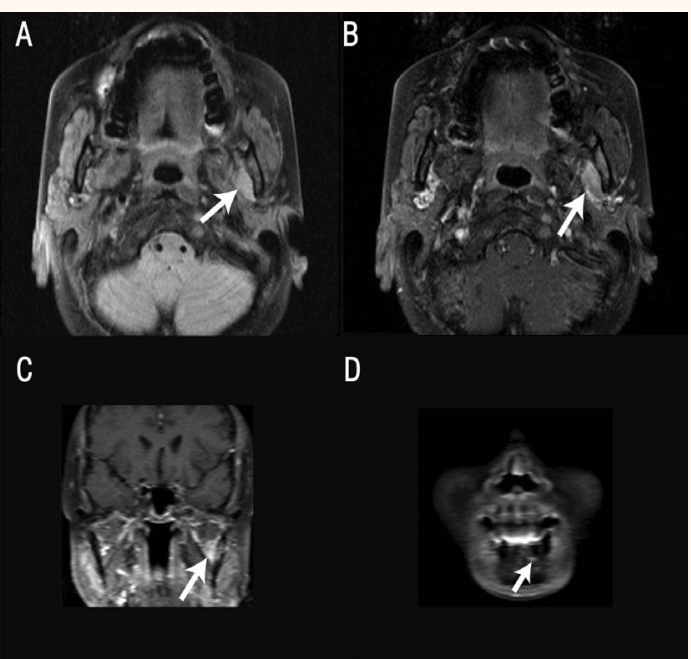

Figure 1: Axial T1-weighted magnetic resonance imaging of a 56-year-old female patient with sudden-onset numbness of the lower lip. The (A) pre-contrast and (B) post-contrast scans show an enhancing mass in the medial left mandibular ramus extending into the bone marrow through the mandibular canal. Coronal views at the level of $(\mathbf{C})$ the mandibular ramus and (D) left mental nerve area show soft tissue enhanced signals near the left mandibular foramen (arrows).

been diagnosed with immunoglobulin A- $\lambda$ MM, after presenting with anaemia, hypercalcaemia, acute renal insufficiency and a compression fracture of the T12 vertebra. Her initial symptoms included pain related to the long bones and back. She went into complete remission after being treated with bortezomib, dexamethasone and high-dose melphalan followed by an autologous stem cell transplantation in 2009. Posttransplant, she remained in complete remission and was prescribed maintenance thalidomide therapy.

At referral, the patient was not in any pain and a comprehensive dental examination indicated a good oral status with multiple heavily restored teeth. No evidence of infection or dental pathology was noted. The numbness affected the left side of the lower lip, chin and gingivae of the $32^{\text {nd }}$ to $36^{\text {th }}$ teeth. An orthopantomogram and a computed tomography scan showed no evidence of dental or maxillofacial pathology. Based on the clinical presentation, examination and the patient's medical status, the possibility of a relapse of MM was strongly suspected. An urgent magnetic resonance imaging (MRI) examination of the mandible showed an enhancing soft tissue mass in the medial aspect of the left mandibular ramus extending to the bone marrow through the mandibular canal and a soft tissue enhancement near the left mental nerve at the opening of the mental foramen [Figure 1].

A bone marrow aspiration revealed the presence of over $24 \%$ plasma cells. A biopsy of the oral cavity

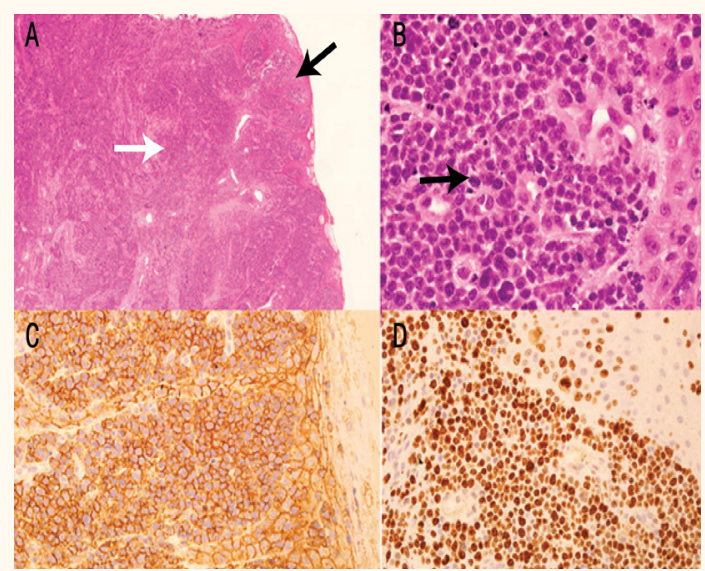

Figure 2: Histopathology images of a plasmablastic myeloma in the oral mucosa. A: Haematoxylin and eosin stain at x40 magnification showing a diffuse cellular neoplastic infiltrate (white arrow) beneath the oral mucosa (black arrow). B: Haematoxylin and eosin stain at x600 magnification displaying plasmablasts with scant cytoplasm, enlarged nuclei with vesicular chromatin and a single nucleolus and frequent mitosis (arrow) and apoptosis. C: 3,3'-Diaminobenzidine immunohistochemistry stain at x400 magnification indicating the immunoreactivity of the cells to cluster of differentiation (CD) 138. D: Stain showing the immunoreactivity of the neoplastic cells to CD138 with a Ki67 proliferation index of $>90 \%$.

lesion showed sheets of plasma cells with plasmablastic morphology and a cellular submucosal infiltrate of the neoplastic plasma cells. The cells were positive for cluster of differentiation (CD) 138 and negative for CD20, CD79a and Epstein-Barr virus, thus excluding a diagnosis of plasmablastic lymphoma. The aggressive nature of the proliferation was supported by the presence of frequent mitosis and a Ki67 proliferation index of $>90 \%$ [Figure 2]. In combination, these findings confirmed the diagnosis of a relapse of MM both in the bone marrow as well as at extramedullary sites, as indicated by the numbness of the left mental nerve and the soft tissue mass in the left retromolar area. Both the morphological and immunophenotypical features of the oral lesion and bone marrow aspirate histopathology specimens indicated that the relapse was a more aggressive form of the disease.

Over the course of the following weeks, the retromolar mass continued to enlarge and became erythematous and ulcerated [Figure 3]. The patient received lenalidomide and dexamethasone but showed no response to treatment. She was subsequently prescribed a bortezomib-based regimen. However, her condition continued to worsen and she developed multiple infections and extramedullary lesions in the shoulder and lungs. The patient died eight months after the diagnosis of a relapse of MM. 


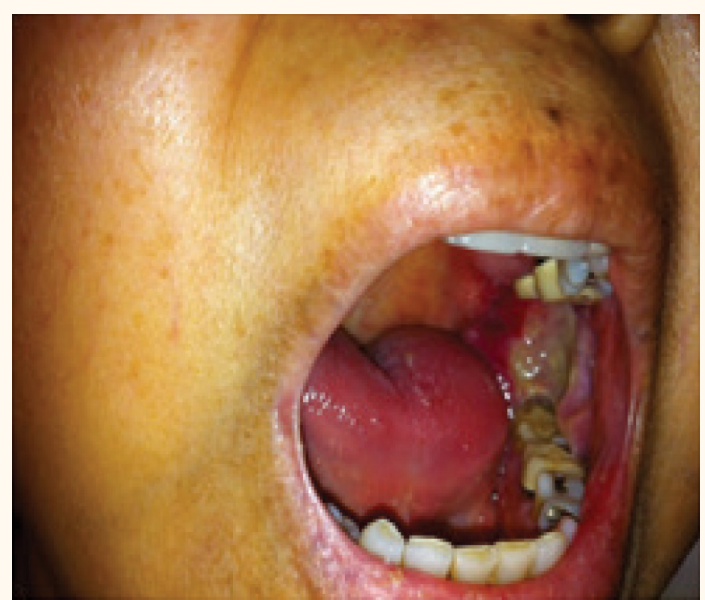

Figure 3: Photograph of a 56-year-old female patient with sudden-onset numbness of the lower lip showing an intra-oral erythematous and ulcerated swelling in the left retromolar region. The lesion extended from the distal aspect of the left second molar with involvement of the lingual and lateral pharyngeal area.

\section{Discussion}

$\mathrm{MM}$ is an uncommon haematological malignancy of the plasma cells which accounts for approximately $10 \%$ of all haematological malignancies. ${ }^{1,8}$, It is diagnosed following the proliferation of clonal plasma cells in the bone marrow or an extramedullary lesion (i.e. plasmacytoma), the presence of a monoclonal protein or light chain and end-organ damage, indicated by hypercalcaemia, renal insufficiency, anaemia and bony lesions. ${ }^{2,10}$ The incidence of MM occurring in the maxillofacial region as either a primary manifestation or relapse is low, with few reported cases. ${ }^{4,11-13}$ Usually, MM appears via imaging as radiolucency in the jaw and the patient may also complain of pain, swelling and mobile teeth. ${ }^{3,13}$ In the present case, the patient was in complete remission when she presented with lip numbness. Initial assessment and routine imaging failed to identify the cause of this sudden neuropathy; however, an MRI scan revealed an altered soft tissue signal with a mass in relation to the inferior alveolar and mental nerves. Similar reported cases of head and neck neuropathies have been observed in patients presenting with primary or secondary EMM..$^{8,9,14-16}$

Histopathology of relapsed MM usually reveals numerous immature plasmablastic cells with pleomorphic cellular features indicating its progression and aggressiveness. ${ }^{8}$ Recent advances in therapy-for instance, the introduction of thalidomide and lenalidomide as treatments for $\mathrm{MM}$-may contribute to increases in the incidence of EMM. ${ }^{6,8}$ These drugs have been shown to have antiangiogenic and immunomodulatory effects that alter the production of interleukin- 6 and tumour necrosis factor- $\alpha$; this in turn decreases the adhesion of plasma cells, resulting in the dissemination of plasma cells away from their original environment and into extramedullary sites. ${ }^{5}$ In the current case, the plasma cells showed aggressive behaviour and diffuse neoplastic infiltration into the oral mucosa via histopathology. These cellular features, along with a loss of the CD138 marker, although this was not seen in the present case, generally result in a high-grade malignancy that responds poorly to treatment. . $^{5,17}$

Bladé et al. and Damaj et al. have reported that progression of MM into EMM is seen in 15-20\% of patients, with an increased frequency in recent years. ${ }^{18,19}$ Relapsing EMM seems to exhibit aggressive behaviour since it manifests as a progression of the disease, leading to a poor prognosis despite various treatment modalities. ${ }^{17,19}$ In addition, survival following an EMM relapse reportedly varies between 4-30 months. ${ }^{20-22}$ In the current case, the patient responded poorly to treatment, developed new lesions at multiple sites and survived for only eight months following the diagnosis. Similar findings have been noted in previous reports. ${ }^{18,20-22}$ As such, a high index of suspicion is needed when treating patients with a previous history of MM, even during remission.

\section{Conclusion}

Relapse of MM in the oral and maxillofacial region is rare. Dental and maxillofacial surgeons should have a high index of suspicion when treating patients with a previous history of neoplastic disease. Such patients should be evaluated by thorough clinical and radiographic examinations to determine the cause of any new symptoms developing, even if they are currently in remission.

\section{References}

1. Ramaiah KK, Joshi V, Thayi SR, Sathyanarayana P, Patil P, Ahmed Z. Multiple myeloma presenting with a maxillary lesion as the first sign. Imaging Sci Dent 2015; 45:55-60. doi: 10.5624/ isd.2015.45.1.55

2. Al-Farsi K. Multiple myeloma: An update. Oman Med J 2013; 28:3-11. doi: 10.5001/omj.2013.02.

3. Nam KU, Ahn J, Hong J. Occurrence of multiple myeloma in the head and neck: A report of two cases. J Korean Assoc Oral Maxillofac Surg 2013; 39:139-43. doi: 10.5125/ jkaoms.2013.39.3.139.

4. Chakravarti A, Vishwakarma SK, Arora VK. Plasmacytoma of the maxilla. Indian J Otolaryngol Head Neck Surg 1997; 49:44-6. doi: 10.1007/BF02991711.

5. Pagella F, Canzi P, Matti E, Benazzo M. Sudden clinical course of an unusual ENT tumour: Clinical pictures of extramedullary plasmacytoma secondary to multiple myeloma. Acta Otorhinolaryngol Ital 2013; 33:347-9. 
6. Besse L, Sedlarikova L, Greslikova H, Kupska R, Almasi M, Penka M, et al. Cytogenetics in multiple myeloma patients progressing into extramedullary disease. Eur J Haematol 2016; 97:93-100. doi: 10.1111/ejh.12688.

7. Fernandez LA, Couban S, Sy R, Miller R. An unusual presentation of extramedullary plasmacytoma occurring sequentially in the testis, subcutaneous tissue, and heart. Am J Hematol 2001; 67:194-6. doi: 10.1002/ajh.1106.

8. Cerny J, Fadare O, Hutchinson L, Wang SA. Clinicopathological features of extramedullary recurrence/relapse of multiple myeloma. Eur J Haematol 2008; 81:65-9. doi: 10.1111/j.16000609.2008.01087.x

9. Hogan MC, Lee A, Solberg LA, Thomé SD. Unusual presentation of multiple myeloma with unilateral visual loss and numb chin syndrome in a young adult. Am J Hematol 2002; 70:55-59. doi: 10.1002/ajh.10077.

10. Al-Farsi K, Al-Haddabi I, Al-Riyami N, Al-Sukaiti, R, Al-Kindi S Myelomatous pleural effusion: Case report and review of the literature. Sultan Qaboos Univ Med J 2011; 11:259-64.

11. Waldron J, Mitchell DB. Unusual presentations of extramedullary plasmacytoma in the head and neck. J Laryngol Otol 1988; 102:102-4. doi: 10.1017/S002221510010413X.

12. Bruce KW, Royer RQ. Multiple myeloma occurring in the jaws: A study of 17 cases. Oral Surg Oral Med Oral Pathol 1953; 6:729-44. doi: 10.1016/0030-4220(53)90199-6.

13. Epstein JB, Voss NI, Stevenson-Moore P. Maxillofacial manifestations of multiple myeloma: An unusual case and review of the literature. Oral Surg Oral Med Oral Pathol 1984; 57:267-71. doi: 10.1016/0030-4220(84)90182-8.

14. Ustuner Z, Basaran M, Kiris T, Bilgic B, Sencer S, Sakar B, et al. Skull base plasmacytoma in a patient with light chain myeloma. Skull Base 2003; 13:167-71. doi: 10.1055/s-2003-43327.
15. Chan KP, Tam CS. Plasmacytoma: Report of a case. Cancer 1969; 23:694-8. doi: 10.1002/1097-0142(196903)23:3<694::AID-CN CR2820230324>3.0.CO;2-8.

16. Nobler MP. Mental nerve palsy in malignant lymphoma. Cancer 1969; 24:122-7. doi: 10.1002/1097-0142(196907) 24:1<122::AID-CNCR2820240116>3.0.CO;2-X.

17. An SY, An CH, Choi KS, Heo MS. Multiple myeloma presenting as plasmacytoma of the jaws showing prominent bone formation during chemotherapy. Dentomaxillofac Radiol 2013; 42:20110143. doi: 10.1259/dmfr.20110143.

18. Bladé J, Kyle RA, Greipp PR. Presenting features and prognosis in 72 patients with multiple myeloma who were younger than 40 years. Br J Haematol 1996; 93:345-51. doi: 10.1046/j.13652141.1996.5191061.x.

19. Damaj G, Mohty M, Vey N, Dincan E, Bouabdallah R, Faucher $\mathrm{C}$, et al. Features of extramedullary and extraosseous multiple myeloma: A report of 19 patients from a single center. Eur J Haematol 2004; 73:402-6. doi: 10.1111/j.16000609.2004.00331.x

20. Nolan KD, Mone MC, Nelson EW. Plasma cell neoplasms: Review of disease progression and report of a new variant. Surg Oncol 2005; 14:85-90. doi: 10.1016/j.suronc.2005.05.001.

21. KatodritouE, Gastari V, VerrouE, Hadjiaggelidou C, VarthalitiM, Georgiadou S, et al. Extramedullary (EMP) relapse in unusual locations in multiple myeloma: Is there an association with precedent thalidomide administration and a correlation of special biological features with treatment and outcome? Leuk Res 2009; 33:1137-40. doi: 10.1016/j.leukres.2009.01.036.

22. Usmani SZ, Heuck C, Mitchell A, Szymonifka J, Nair B, Hoering A, etal. Extramedullary disease portends poor prognosis in multiple myeloma and is over-represented in high-risk disease even in the era of novel agents. Haematologica 2012; 97:1761-7. doi: 10.3324/haematol.2012.065698. 